\title{
Challenges of Implementing and Utilizing Effective BLS According to European Resuscitation Council Guidelines in The Country of Georgia.
}

\section{Giorgi Beria, Lela Tabidze. \\ Skills Laboratory and Training Center - New Vision University, Tbilisi, Republic of Georgia.}

\section{Purpose of the Study}

Georgia faces numerous challenges when implementing BLS according to ERC trainings. Purpose is to investigate controversy regarding availability of BLS trainings one hand and obstacles to provide high quality CPR on the other hand, in particular:

* Survey public awareness/demand of BLS Trainings;

* Investigate availability of AED and 112 phone consultations for cases;

* Describe reasons behind absence of AEDs in public and private institutions;

* Outline general findings and recommendations.

\section{Materials and Methods}

Public and private sector, selected by randomized study, were evaluated with a questionnaire, which was given via an online platform $(35 \%)$ and on site visit (65\%) ensuring anonymity. Also, was offered to administrative representatives, 112 employees and various institutions of frequent public use.

\section{RESULTS}

Total 318 employees and managers has been responded in 10 different institution of 3 main areas:

1) Emergency Response Service (ERS) - 9\%;

2) Business, maintenance service and field workers - 30\%;

3 ) academic and office staff $-55 \%$;

4) Emergency phone call 112 Staff - 6\%.

There are $22 \%$ having BLS training even one time, where portion of ERS in 100\% (mandatory by government). Other institutions has low range over $18 \%$, however readiness among responders to be trained reaches $82.6 \%$, which means that the demand of training exists, but there's still low supply.

The main obstacles to provide high quality CPR among trained personal is absence of AED in the country, $100 \%$ of our respondents don't have AED in their institutions. even skillful BLS providers like ERS (rescuers only) can't perform high quality CPR, they're trained how to use AED, but don't have it.

From the rest of the staff, who think that are able to provide BLS, only $12 \%$ knows how to use AED. $28 \%$ heard, but can't use it, $60 \%$ never have heard about the device. We tried to identify reason of it's absence, $46 \%$ of trained top managers thinks whether it's not necessary (17\%) or don't know importance (29\%); Also $21 \%$ think that it's a medical tool and should be used only by doctors.

Can be concluded, that absence and low quality of training is the most reason of not purchasing AED. Next most common cause is it's high price.

Another challenge for effective CPR according ERC guidelines is emergency service -112 phone call consultation. $90 \%$ of 112 staff claims that they never have BLS or specialized training to consulate rescuers. In the internal procedure there is general and unclear indication about consultation.

\section{Conclusion}

As it turned out the main source of low quality CPR in Georgia is absence of trainings or low quality trainings. Even trained people are not aware about AED and without AED even skillful provider's can't perform high quality CPR. AEDs won't be purchased and implemented unless importance won't be proved by qualified trainings, which is an element of rising of society awareness demanding AEDs. Spread of BLS trainings in it's turn will motivate development of public policy and need for effective 112 phone consultation as well.

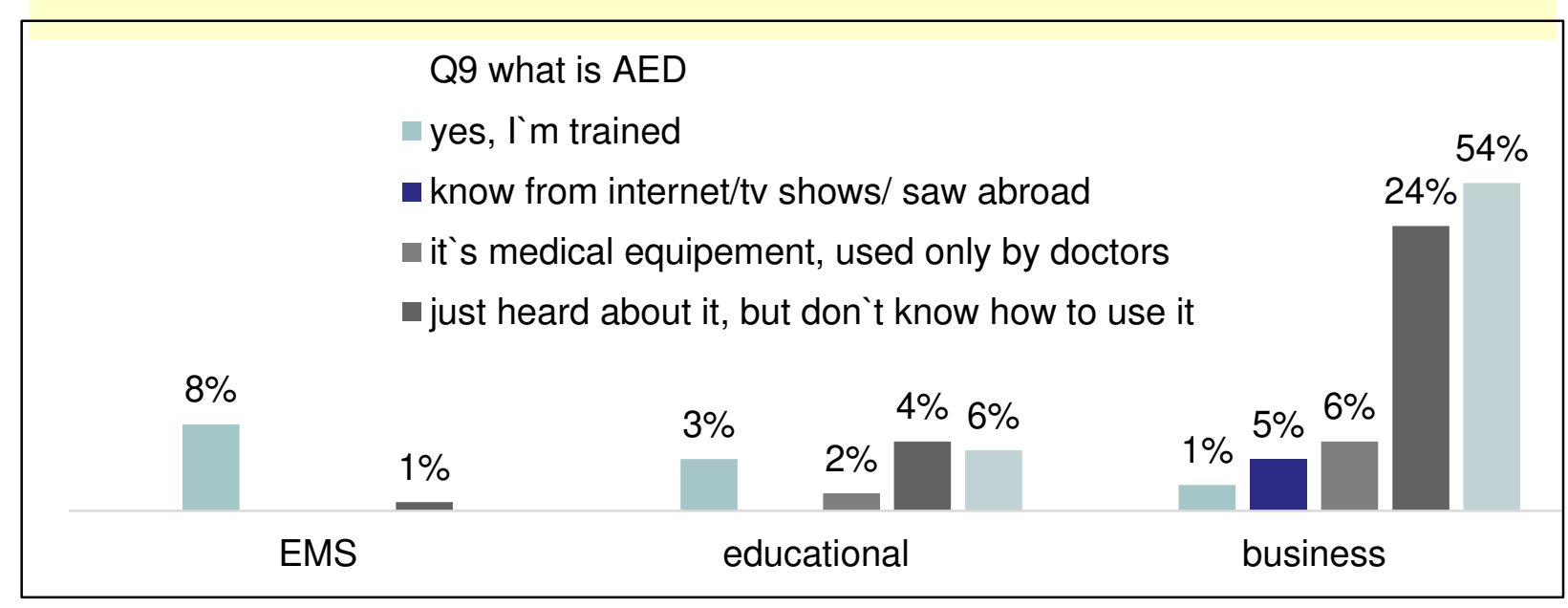

\section{Q10 Do you have AED}

$50 \%$

- I've never asked, because I don`t know about it

- don`t know, because manager haven`t provided information -we don`t have it

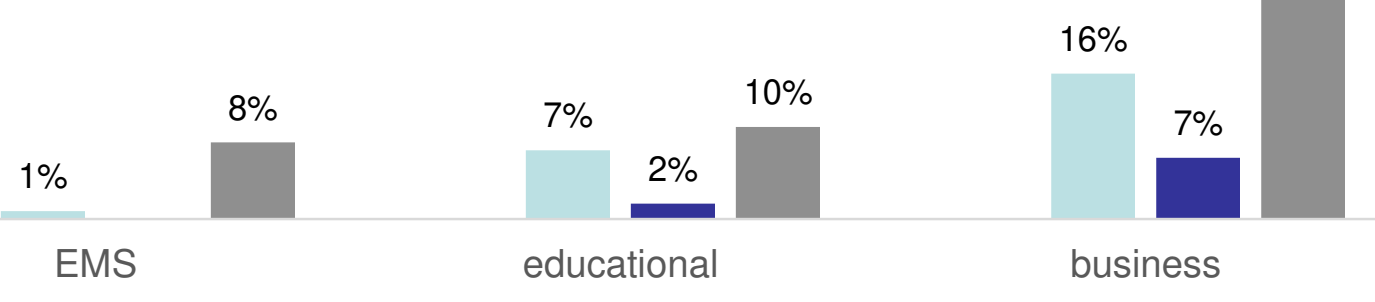

Q11 want to be trained

yes, everyone should know it

- yes, because I witnessed someones death and couldn`t help
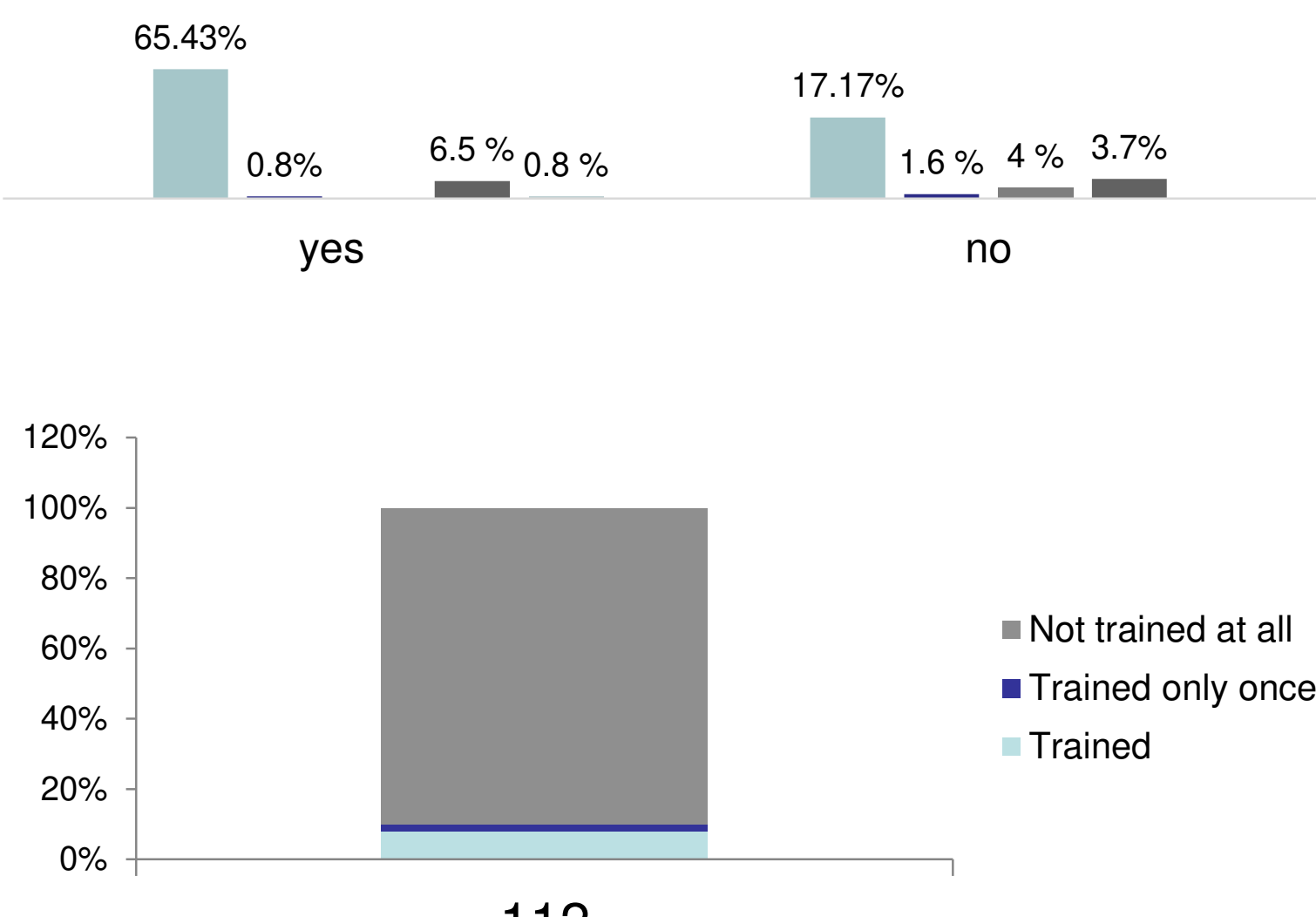

112 